\title{
Epidemiology and liver transplantation burden of primary biliary cholangitis: a retrospective cohort study
}

\author{
Eric M. Yoshida MD, Andrew Mason MD, Kevork M. Peltekian MD, Hemant Shah MD, \\ Sherri Thiele PhD, Richard Borrelli MBA, Aren Fischer MSc
}

\section{Abstract}

Background: There is a wealth of data documenting the epidemiology of primary biliary cholangitis (PBC) globally; however, the epidemiology of PBC has not been as well studied in Canada. Our study characterized the Canadian prevalence of PBC and the number of liver transplantations because of PBC.

Methods: For this retrospective cohort study we used national hospital administrative records from the Canadian Institute for Health Information, with the exception of Quebec for the prevalence estimate and Quebec and British Columbia for the transplant analysis. Prevalent patients were identified through a diagnostic code for PBC of the Canadian version of the 10th revision of the International Classification of Diseases. PBC transplant patients were identified from their transplant record. Descriptive statistics were used to summarize the characteristics of the study cohorts.

Results: In 2015, 8680 patients with PBC were identified in Canada, translating to a prevalence of 318 cases per million. Annual prevalence by province varied, ranging from 283 (95\% confidence interval [Cl] 269-297) cases per million to 465 (95\% Cl 426-504) cases per million, and the 6-year PBC liver transplantation rate ranged from 3.17 (95\% Cl 1.27-6.54) to 5.92 (95\% Cl 3.71-9.08) per million. The Atlantic provinces exhibited the highest PBC prevalence and close to the highest 6-year liver transplantation rate (465 [95\% Cl 426-504] cases per million and 5.70 [95\% Cl 426-504, 3.19-9.56] cases per million, respectively). We observed the lowest PBC prevalence (283 [95\% Cl 269-297] cases per million) and the second lowest 6-year liver transplantation rate in Ontario (3.37 [95\% Cl 2.47-4.50] cases per million).

Interpretation: The prevalence of PBC that we found in Canada is similar to the prevalence reported in other studies, but our work also indicates geographic variation within this country. Given our finding of geographic clustering of PBC across Canada, we hypothesize that environmental and genetic factors contribute to the pathogenesis of this condition.

$\mathrm{P}$ rimary biliary cholangitis (PBC) is a rare chronic autoimmune cholestatic liver disease characterized by destruction of the small intrahepatic bile ducts. It predominantly affects middle-aged and elderly women. ${ }^{1,2}$ Despite its rarity, PBC is an important cause of liver-related morbidity..$^{2-5}$ In the United States, the annual economic burden of PBC has been estimated to be $\$ 69-\$ 115$ million. ${ }^{3}$ There is concern that the economic impact of PBC could increase significantly in the future because of the increasing incidence and prevalence of this disease; ${ }^{6-12}$ however, with improved treatment options, the costs may be attenuated. ${ }^{13-15}$ The epidemiology of PBC was first described as early as 40 years ago, ${ }^{16}$ although decades later no study has yet investigated the national prevalence of $\mathrm{PBC}$ in Canada. A number of studies have examined the epidemiology of PBC globally, illustrating considerable variability in the prevalence of the disease; prevalence rates range from 6.7 to 402 cases per million, while incidence rates range from 0.7 to 58 cases per million. ${ }^{1}$ A growing number of studies suggest that the incidence and prevalence of $\mathrm{PBC}$ are increasing. ${ }^{6-12}$ The driver of this growth remains unclear, but it may be the result of an increase in incidence, longer survival and

Competing interests: Eric Yoshida has been an investigator of clinical trials sponsored by Intercept, Gilead, Merck, Janssen, AbbVie, Genfit and Spring Bank. He has received speaker fees from Gilead, Merck, AbbVie, Celgene and Intercept. Andrew Mason reports receiving grants from Intercept, Merck, Gilead, AbbVie, Novartis and GlaxoSmithKline during the conduct of the study and grants from Intercept, Merck, Gilead and AbbVie outside the submitted work. He has received advisory board and speaker fees from Intercept. Kevork Peltekian is a member of the national board of directors of the Canadian Liver Foundation. Hemant Shah has received advisory board and speaker fees from AbbVie, Gilead, Intercept, Lupin and Merck.

This article has been peer reviewed.

Correspondence to: Aren Fischer, Aren.Fischer@ca.imsbrogan.com

CMAJ Open 2018. DOI:10.9778/cmajo.20180029 
advances in diagnosis and treatment. In addition, there is increasing evidence to suggest that the cause of $\mathrm{PBC}$ is related to complex interactions between genetic predisposition and environmental triggers, ${ }^{3,17-21}$ such as infectious disease agents. ${ }^{3,22-25}$

Recent advances in the understanding of $\mathrm{PBC}$ provide the opportunity to improve patient outcomes and to lower the economic and epidemiologic burden of PBC. In this study, the primary objective was to estimate the national prevalence of PBC in Canada. The secondary objective was to characterize liver transplantation trends in $\mathrm{PBC}$ patients and the geographic distribution of these patients, given that this is a costly procedure and a considerable proportion of $\mathrm{PBC}$ patients require liver transplants because of end-stage complications.

\section{Methods}

\section{Data sources and study population}

The study used patient-level records over a 9-year period from Apr. 1, 2007, to Mar. 31, 2015, for the prevalent population and over a 6-year period from Apr. 1, 2010, to Mar. 31, 2015, for the liver transplant population. This study used data from the administrative health care databases of the Canadian Institute for Health Information (CIHI). Information about a visit is recorded in the patient's chart at the time of service in the hospital, and an abstract is completed for every visit to a hospital even if patients receive care from multiple physicians. The data are entered into fields by specialized staff who adhere to a standard coding system. CIHI conducts data quality assessments and also employs several channels to ensure data correctness and reabstraction.

Data from 3 CIHI databases were used in this study. The National Ambulatory Care Reporting System (NACRS) database contains data on hospital-based and communitybased emergency and ambulatory care visits, including visits to day surgery and outpatient clinics in Canada. ${ }^{26}$ The Discharge Abstract Database (DAD) contains data on hospital admissions from acute inpatient care and select day surgery, chronic, rehabilitation and psychiatric institutions in Canada. ${ }^{27}$ The Canadian Organ Replacement Register (CORR) contains information on all transplanted organs across Canada. ${ }^{28}$

Data from 9 of 10 provinces in Canada, with the exception of Quebec, were made available for the prevalence estimate, and data from 8 of 10 provinces in Canada, with the exception of British Columbia and Quebec, were made available for the transplant analysis. For the provinces with incomplete data coverage or unreleased data we extrapolated results from the other provinces by applying age-adjusted prevalence or transplant rates to the known populations within those provinces as reported by Statistics Canada. ${ }^{39}$ To capture diagnoses made in clinics we used the available data from Alberta to estimate diagnoses in other provinces. Data of individual provinces were then grouped into geographic regions: Atlantic (Nova Scotia, New Brunswick, Prince Edward Island and Newfoundland), Ontario, Prairies (Manitoba and Saskatchewan), Alberta and British Columbia.

\section{Administrative data case definition}

PBC case identification for the prevalent population required 1 hospital visit with a single diagnostic code for PBC (Canadian version of the 10th revision of the International Classification of Diseases K74.3) recorded as the most responsible reason for a visit or as a comorbidity diagnosis for that hospital visit during the study period. PCB diagnoses were identified from either the DAD or NACRS database; the diagnosis was not required to appear in both databases for the same visit, which may otherwise have reduced the number of cases. In all study databases, unique patient identifiers were used to prevent double counting of patients. Similar to previous studies, ${ }^{2,4,5}$ PBC case identification for the liver transplant population required the primary reason for the transplant to be PBC.

\section{Indexes of liver disease severity}

Alberta patients were further identified as having late-stage $\mathrm{PBC}$ if their medical records included at least 1 diagnosis associated with late-stage PBC. This additional analysis was limited to Alberta because it was the only province where the administrative databases had full coverage of outpatient clinics and hospital visits, which is required for a robust determination of late-stage disease. ${ }^{36}$ The list of diagnosis codes associated with late-stage PBC was generated using published literature ${ }^{18,34,40}$ and expert clinical opinion. ${ }^{41}$

For the liver transplant population, the Model for EndStage Liver Disease (MELD) score and the Child-Pugh score were used as a measure of prognostic survival and liver disease severity, and they are traditionally used to determine liver transplant priority. ${ }^{42}$ The MELD score uses the patient's values for serum bilirubin, serum creatinine and the international normalized ratio for prothrombin time. ${ }^{43}$ The Child-Pugh score employs 5 clinical measures of liver disease: total bilirubin, serum albumin, prothrombin time, ascites and hepatic encephalopathy. Each measure is scored between 1 and 3, with 3 indicating the most severe condition. ${ }^{42}$

\section{Statistical analysis}

The prevalence estimate was evaluated between Apr. 1, 2013, and Mar. 31, 2015, for the prevalent population and between Apr. 1, 2010, and Mar. 31, 2015, for the liver transplant population. The annual prevalence was determined by dividing the number of patients with PBC alive on Mar. 31 for each year by the populations for each geographic area (from Statistics Canada data). Owing to the disease's chronic nature, patients were considered prevalent with PBC until a hospital death occurred. Our study used all available history in the look-back period to establish prevalence. To determine the geographic distribution of the PBC liver transplant population, we used an estimate of the 6-year liver transplant rate per million because annual transplant rates are low. Regional estimates were age and sex adjusted to the 2015 and 2013 Canadian populations for the prevalent and liver transplant populations, respectively. ${ }^{44}$ These reference years for adjustment were chosen on the basis of the data that were available to provide estimates for the most recent reporting 
year. Wait time for liver transplantation was defined as the number of days from the date that the patient was placed on the transplant list to the date of liver transplant. Patients who died while on the transplant list were not included in CORR and their data were therefore unavailable for analysis. Descriptive statistics were used to summarize the characteristics of the study cohorts. We calculated $p$ values between prevalence estimates using the 2-sided Wilson method with a continuity correction. The Kaplan-Meier method was used to assess transplant wait time and survival.

\section{Ethics approval}

Our study received ethics approval from the Advarra Center for IRB Intelligence (ethics registration no. Pro00017376), and the research ethics plan was approved by CIHI.

\section{Results}

\section{National prevalence of primary biliary cholangitis}

In 2015, 8680 patients with PBC were identified in Canada, excluding Quebec, which translates into a prevalence of 318 (95\% confidence interval [CI] 309-327) cases per million (Table 1). The prevalence of PBC varied across the country. In 2015, the Atlantic provinces had the highest PBC prevalence (465 [95\% CI 426-504] cases per million) in Canada, followed by the Prairie provinces (399 [95\% CI 360-438] cases per million), British Columbia (327 [95\% CI 302-352] cases per million), then Alberta (292 [95\% CI 275-309] cases per million). The lowest prevalence was observed in Ontario (283 [95\% CI 269-297] cases per million) (Table 1). Relative to Ontario, the Atlantic provinces $(p<0.01)$, the Prairie provinces $(p<0.01)$ and British Columbia $(p<0.05)$ had a significantly higher PBC prevalence. However, the prevalence in Alberta was not significantly different from that in Ontario $(p=0.4)$.

The demographic characteristics of the PBC population are shown in Table 2. PBC was approximately 4 times as

\begin{tabular}{|c|c|c|}
\hline \multirow[b]{2}{*}{ Year } & \multicolumn{2}{|c|}{$\begin{array}{l}\text { Prevalence, no. per million population* } \\
\qquad(95 \% \mathrm{Cl})\end{array}$} \\
\hline & Patients with PBC & $\begin{array}{l}\text { Liver transplantation } \\
\text { in patients with PBC }\end{array}$ \\
\hline 2010 & - & $1.03(0.93-1.06)$ \\
\hline 2011 & - & $0.55(0.37-0.73)$ \\
\hline 2012 & - & $1.02(0.92-1.11)$ \\
\hline 2013 & 255 (248-264) & $0.59(0.47-0.71)$ \\
\hline 2014 & 288 (279-297) & $0.58(0.52-0.65)$ \\
\hline 2015 & 318 (309-327) & $0.49(0.41-1.06)$ \\
\hline
\end{tabular}

\begin{tabular}{|lcc|}
\hline \multicolumn{3}{|l|}{$\begin{array}{l}\text { Table 2: Demographics of patients with } \\
\text { primary biliary cholangitis in }\end{array}$} \\
\hline $\begin{array}{l}\text { Age group, } \\
\text { yr }\end{array}$ & $\begin{array}{c}\text { Male } \\
\text { no. }(\%)\end{array}$ & $\begin{array}{c}\text { Female } \\
\text { no. }(\%)\end{array}$ \\
\hline $0-17$ & $16(62)$ & $10(38)$ \\
\hline $18-39$ & $224(35)$ & $416(65)$ \\
\hline $40-64$ & $936(20)$ & $3764(80)$ \\
\hline $65-79$ & $574(22)$ & $2083(78)$ \\
\hline$\geq 80$ & $113(17)$ & $544(83)$ \\
\hline
\end{tabular}

common among females in our study population. In females, $\mathrm{PBC}$ was most frequently diagnosed in the 40- to 64-year age group. $\mathrm{PBC}$ was more common in females than males in all but the youngest age group (0-17 yr). Disease severity varied by province. Of the Alberta patients with PBC, 29\% (95\% CI $26 \%-32 \%)$ were identified as having late-stage PBC as indicated by a diagnosis associated with late-stage disease. When we further segmented the population by treatment location, we found that $8 \%(95 \%$ CI $6 \%-10 \%)$ of patients with PBC treated only in a clinic were identified as having late-stage disease, whereas $48 \%$ (95\% CI $44 \%-53 \%$ ) of patients who received a $\mathrm{PBC}$ diagnosis in the hospital were considered to have late-stage disease.

\section{National liver transplantation rates for primary biliary cholangitis}

A total of 92 patients received a liver transplant because of PBC between Apr. 1, 2010, and Mar. 31, 2015, in Canada (excluding Quebec and British Columbia), accounting for $5 \%$ of all liver transplants in this time frame. The annual rate of liver transplantation because of $\mathrm{PBC}$ varied and ranged from 0.49 to 1.03 cases per million in the general population (Table 1). The geographic analysis showed that the 6-year liver transplant rate per million because of $\mathrm{PBC}$ was highest in Alberta (5.92 [95\% CI 3.71-9.08] cases per million) followed by the Atlantic provinces (5.70 [95\% CI 3.19-9.56] cases per million), then Ontario (3.37 [95\% CI 2.47-4.50] cases per million). The lowest 6-year liver transplant rate per million because of $\mathrm{PBC}$ was observed in the Prairie provinces (3.17 [95\% CI 1.27-6.54] cases per million). Relative to Ontario, Alberta had a significantly higher 6-year PBC liver transplantation rate per million $(p<0.05)$. However, the rates in the Atlantic $(p=0.1)$ and Prairie $(p=1)$ provinces did not differ significantly from the rate in Ontario.

Liver transplants were approximately 5 times more common among females than among males, which aligns with our findings in the PBC prevalence analysis. Furthermore, among all diagnoses, $\mathrm{PBC}$ was the leading cause of liver transplantation in females. Among males and females in this study, the highest number of liver transplants was observed in patients between the ages of 40 and 64 years (Table 3). Close to half of patients with $\mathrm{PBC}$ who received a liver transplant had the most severe liver dysfunction as measured by a Child-Pugh 


\begin{tabular}{|c|c|c|c|}
\hline \multicolumn{4}{|c|}{$\begin{array}{l}\text { Table 3: Demographics and disease severity } \\
\text { of patients with primary biliary cholangitis } \\
\text { liver who received a liver transplant in } \\
2010-2015\end{array}$} \\
\hline Variable & $\begin{array}{c}\text { Male } \\
\text { no. (\%) }\end{array}$ & $\begin{array}{l}\text { Female } \\
\text { no. (\%) }\end{array}$ & $\begin{array}{c}\text { All } \\
\text { no. (\%) }\end{array}$ \\
\hline \multicolumn{4}{|l|}{ Age, $\mathrm{yr}^{*}$} \\
\hline $0-17 \dagger$ & $<5(13)$ & 0 & \\
\hline 18-39 & 0 & $8(11)$ & \\
\hline $40-64$ & $13(54)$ & $58(83)$ & \\
\hline$\geq 65$ & $8(33)$ & $4(6)$ & \\
\hline \multicolumn{4}{|c|}{ Child-Pugh category $\ddagger$} \\
\hline $5-6$ & & & 0 \\
\hline $7-9$ & & & $12(41)$ \\
\hline $10-15$ & & & $17(58)$ \\
\hline \multicolumn{4}{|c|}{ MELD category $\ddagger$} \\
\hline$<12 \dagger$ & & & $<5(7)$ \\
\hline $12-16$ & & & $10(24)$ \\
\hline $17-22$ & & & $12(29)$ \\
\hline$>22$ & & & $<5(39)$ \\
\hline \multicolumn{4}{|c|}{$\begin{array}{l}\text { Note: MELD = model of end-stage liver disease. } \\
{ }^{*} \text { These data show the crude unadjusted counts for the liver } \\
\text { transplant population by age. } \\
\text { †Counts } \leq 5 \text { are masked. Percentages were estimated by } \\
\text { assuming a count of } 3 \text { for the masked category. } \\
\text { fThese data show the distribution of disease severity as } \\
\text { measured by Child-Pugh and MELD scores. }\end{array}$} \\
\hline
\end{tabular}

score of $10-15(58 \%)$ and a MELD score of > $22(39 \%)$ (Table 3).

When we analyzed wait times to receive a transplant, the median wait time for patients with PBC was 2 months $(95 \%$ CI 1-3) (Figure 1). After transplantation, the 2-year survival for patients with $\mathrm{PBC}$ was estimated to be $89 \%$ (95\% CI $83 \%-96 \%$ ) (Figure 1).

\section{Interpretation}

This study improves upon previous studies estimating the regional or local prevalence of $\mathrm{PBC}$ by describing national epidemiologic trends of $\mathrm{PBC}$ and associated liver transplants across Canada. We found that the annual prevalence of $\mathrm{PBC}$ varied by province from 283 (95\% CI 269-297) to 465 (95\% CI 426-504) cases per million, and the 6-year PBC liver transplant count ranged from 3.17 (95\% CI 1.27-6.54) to 5.92 (95\% CI 3.71-9.08) per million. The last time the prevalence of $\mathrm{PBC}$ in the US was reported was for the period of 1975-1995. ${ }^{9}$ Previous prevalence studies of PBC produced a wide range of estimates, ranging from 6.7 to 402 per million. $1,7,9-12,16,45$ The PBC prevalence figures reported in this study (prevalence of 318 cases per million in 2015) are among the highest ones reported, and when they are projected nationally to extrapolate for the Quebec population they correspond to 11290 prevalent PBC cases in Canada in 2015.
Earlier Canadian studies ${ }^{11,12}$ reported prevalence estimates of between 3 and 25 per million, an order of magnitude lower than the current study. The most recent Canadian estimate, which focused on Alberta, reported a prevalence of 227 per million in $2002,{ }^{10}$ which is consistent with our estimate of the PBC prevalence in Alberta (292 per million).

Several factors may be contributing to the increase in PBC prevalence: greater disease awareness and testing, earlier diagnosis and prolonged survival. Several studies on the temporal trends of liver transplants and the outcomes of patients with PBC suggest that prolonged survival may be a key factor. ${ }^{9,33,46,47}$ Lee and colleagues described a reduction in the number of transplantations for patients with $\mathrm{PBC}$, thought to be attributed to the introduction of ursodeoxycholic acid, possibly indicating improved outcomes and therefore prolonged survival. $9,33,48$

Our geographic analysis showed large disparities in the PBC prevalence across Canadian provinces, ranging from 283 to 465 cases per million for the prevalence analysis and from 3.17 to 5.92 liver transplants per million in the general population for the liver transplant analysis. Notably, the Atlantic provinces had a high PBC prevalence (465 per million) and 6-year $\mathrm{PBC}$ liver transplant rate per million (5.70 per million), demonstrating geographic clustering of $\mathrm{PBC}$ in this region. We postulate that this could be explained by a founder effect given that a large percentage of the Atlantic population are descendants of immigrants from the United Kingdom and northern France, and it has been demonstrated that the UK has one of the highest $\mathrm{PBC}$ prevalence rates. ${ }^{1}$ Approximately $29 \%$ of Newfoundland and Labrador's, $19 \%$ of PEI's, $16 \%$ of Nova Scotia's and $12 \%$ of New Brunswick's population descend from immigrants from the UK, with even higher percentages having some UK roots. ${ }^{49}$ In comparison, only $9 \%$ of the Ontario population, the province with the lowest estimated $\mathrm{PBC}$ prevalence, are descendants of immigrants from the UK. ${ }^{49}$ These patterns may suggest genetic and environmental influences on the causes and pathogenesis of $\mathrm{PBC}$.

The literature suggests that $\mathrm{PBC}$ is typically considered a disease of middle age, ${ }^{11,12}$ and our results echoed these findings. Approximately $54 \%$ of patients in the total $\mathrm{PBC}$ prevalent study population were 40-64 years of age. ${ }^{49}$ The liver transplantation survival rate for patients with $\mathrm{PBC}$ in the present analysis (2-yr survival $89 \%$ ) is comparable to the rate in the CORR annual report (5-yr survival $81.8 \%$ ). Fosby and colleagues observed a similar survival rate for PBC liver transplantation in Nordic countries between 2004 and 2013, reporting the 1-year and 5-year survival rates for patients who received transplants for $\mathrm{PBC}$ to be $94 \%$ and $87 \%$, respectively. ${ }^{4}$

\section{Limitations}

As our study has several limitations because of the challenges inherent in using administrative data sets, we recommend careful interpretation of our results. Our study is potentially limited by the risk of misclassification of people with $\mathrm{PBC}$, which could affect our prevalence estimates. The definition 
A

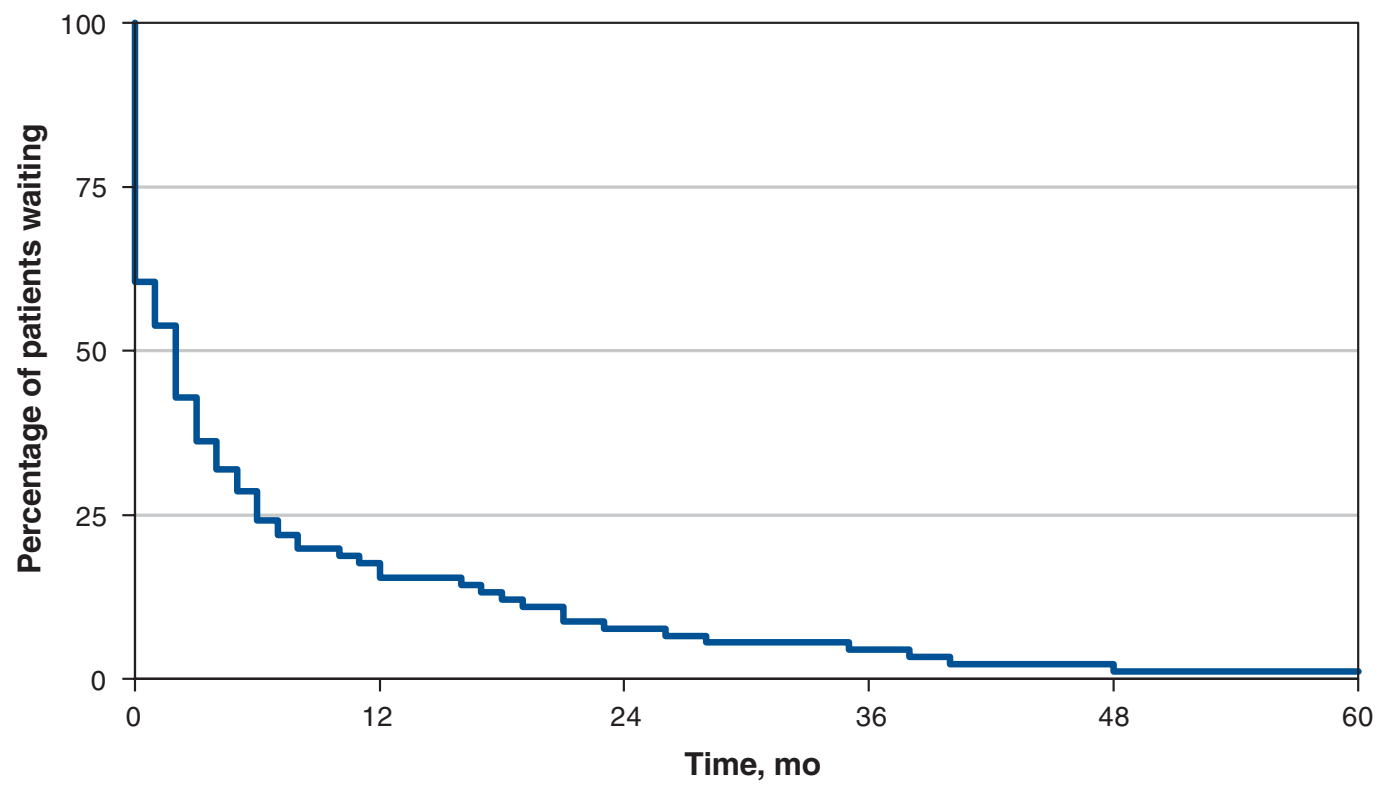

B

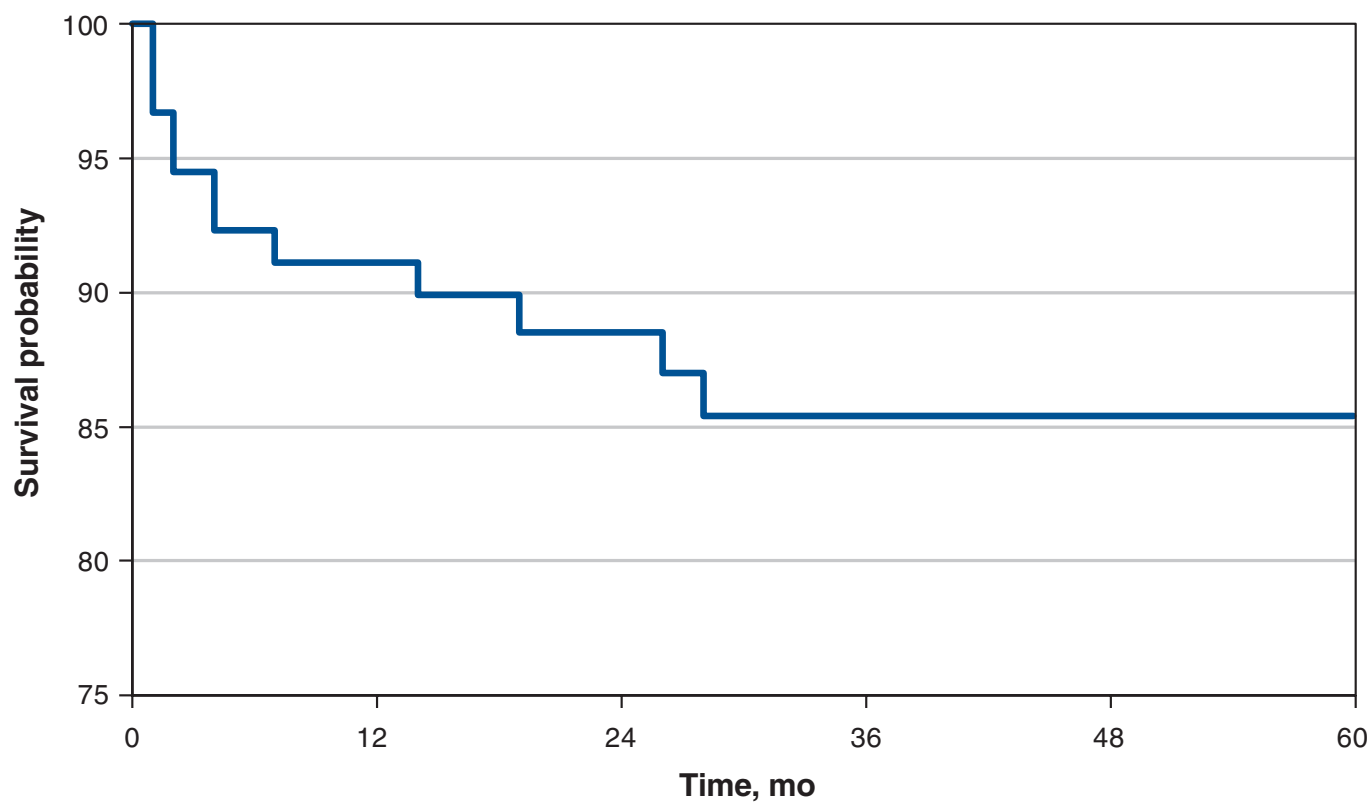

Figure 1: (A) Analysis of wait time for liver transplantation for primary biliary cholangitis, showing the percentage of patients waiting to receive a liver transplant for each month after being listed on the transplant list. (B) Analysis of survival after liver transplantation for primary biliary cholangitis.

used by Myers and colleagues required 2 distinct diagnoses of $\mathrm{PBC}$ and was shown to have a positive predictive value (PPV) of $73 \%$ for definite or probable $\mathrm{PBC}$ cases; $;{ }^{51}$ therefore, we can expect our PPV value would be lower as it was based on a single $\mathrm{PBC}$ diagnosis in this study. Second, the data coverage for the DAD and NACRS (emergency department) 
databases was not complete across the provinces, and therefore the data from one province may not fully represent the data in another. However, the number of patients with PBC identified through the emergency department was small ( $5 \%)$, hence we consider this adjustment to have been minor. For clinic visits, we used Alberta, which had 100\% clinic coverage, to project for lack of visibility in other provinces. In our study $58 \%$ of the PBC population was identified through the clinic, and therefore this part of the projection had a greater impact on the prevalence estimate. Notwithstanding the potential limitations in this study, the authors feel that the challenges inherent in using administrative data were overcome to the extent possible to provide an accurate estimate of $\mathrm{PBC}$ prevalence.

\section{Conclusion}

Using population-based administrative data we have provided insight into the geographic distribution and temporal trends of $\mathrm{PBC}$ in Canada both in terms of the prevalence of $\mathrm{PBC}$ and the rate of liver transplantation in people with the disease. The observed prevalence demonstrates $\mathrm{PBC}$ is a growing health care concern in Canada, and further investigations of the interplay between genetic and environmental influences on PBC disease are warranted.

\section{References}

1. Boonstra K, Beuers U, Ponsioen CY. Epidemiology of primary sclerosing cholangitis and primary biliary cirrhosis: a systematic review. 7 Hepatol 2012; 56:1181-8.

2. Prince $M$, Chetwynd A, Newman $W$, et al. Survival and symptom progression in a geographically based cohort of patients with primary biliary cirrhosis: follow-up for up to 28 years. Gastroenterology 2002;123:1044-51.

3. Gershwin ME, Selmi C, Worman HJ, et al.; USA PBC Epidemiology Group. Risk factors and comorbidities in primary biliary cirrhosis: a controlled interview-based study of 1032 patients. Hepatology 2005;42:1194-202.

4. Neuberger J. Recurrent primary biliary cirrhosis. Liver Transpl 2003; 9:539-46.

5. Fosby B, Melum E, Bjøro K, et al. Liver transplantation in the Nordic countries - an intention to treat and post-transplant analysis from The Nordic Liver Transplant Registry 1982-2013. Scand 7 Gastroenterol 2015; 50:797-808.

6. Charatcharoenwitthaya P, Pimentel S, Talwalkar JA, et al. Long-term survival and impact of ursodeoxycholic acid treatment for recurrent primary biliary cirrhosis after liver transplantation. Liver Transpl 2007;13:1236-45.

7. Hurlburt KJ, McMahon BJ, Deubner H, et al. Prevalence of autoimmune liver disease in Alaska Natives. Am 7 Gastroenterol 2002;97:2402-7.

8. James OF, Bhopal R, Howel D, et al. Primary biliary cirrhosis once rare, now common in the United Kingdom? Hepatology 1999;30:390-4.

9. Kim WR, Lindor KD, Locke GR III, et al. Epidemiology and natural history of primary biliary cirrhosis in a US community. Gastroenterology 2000; 119:1631-6.

10. Myers RP, Shaheen AA, Fong A, et al. Epidemiology and natural history of primary biliary cirrhosis in a Canadian health region: a population-based study. Hepatology 2009;50:1884-92.

11. Villeneuve J-P, Fenyves D, Infante-Rivard C. Descriptive epidemiology of primary biliary cirrhosis in the province of Quebec. Can 7 Gastroenterol 1991;5:174-8. doi: 10.1155/1991/712802.

12. Witt-Sullivan H, Heathcote $\mathrm{J}$, Cauch K, et al. The demography of primary biliary cirrhosis in Ontario, Canada. Hepatology 1990;12:98-105.

13. Lee YM, Kaplan MM. Efficacy of colchicine in patients with primary biliary cirrhosis poorly responsive to ursodiol and methotrexate. Am 7 Gastroenterol 2003;98:205-8

14. Nevens F, Andreone P, Mazzella G, et al.; POISE Study Group. A placebocontrolled trial of obeticholic acid in primary biliary cholangitis. $N$ Engl $7 \mathrm{Med}$ 2016;375:631-43.

15. Carey EJ, Ali AH, Lindor KD. Primary biliary cirrhosis. Lancet 2015; 386:1565-75

16. Hamlyn AN, Sherlock S. The epidemiology of primary biliary cirrhosis: a survey of mortality in England and Wales. Gut 1974;15:473-9.
17. McNally RJ, James PW, Ducker S, et al. No rise in incidence but geographical heterogeneity in the occurrence of primary biliary cirrhosis in North East England. Am 7 Epidemiol 2014;179:492-8.

18. Leung PS, Chuang DT, Wynn RM, et al. Autoantibodies to BCOADC-E2 in patients with primary biliary cirrhosis recognize a conformational epitope. Hepatology 1995;22:505-13.

19. Kimura Y, Selmi C, Leung PS, et al. Genetic polymorphisms influencing xenobiotic metabolism and transport in patients with primary biliary cirrhosis. Hepatology 2005;41:55-63.

20. Cordell HJ, Han Y, Mells GF, et al. International genome-wide meta-analysis identifies new primary biliary cirrhosis risk loci and targetable pathogenic pathways. Nat Commun 2015;6:8019.

21. Ala A, Stanca CM, Bu-Ghanim M, et al. Increased prevalence of primary biliary cirrhosis near Superfund toxic waste sites. Hepatology 2006;43: 525-31

22. Prince MI, Ducker SJ, James OF. Case-control studies of risk factors for primary biliary cirrhosis in two United Kingdom populations. Gut 2010; 59:508-12.

23. Corpechot C, Chrétien Y, Chazouillères O, et al. Demographic, lifestyle, medical and familial factors associated with primary biliary cirrhosis. 7 Hepatol 2010;53:162-9.

24. Zein CO, Beatty K, Post AB, et al. Smoking and increased severity of hepatic fibrosis in primary biliary cirrhosis: a cross validated retrospective assessment. Hepatology 2006;44:1564-71.

25. Mason AL, Zhang G. Linking human beta retrovirus infection with primary biliary cirrhosis. Gastroenterol Clin Biol 2010;34:359-66.

26. Wang J, Yang G, Dubrovsky AM, et al. Xenobiotics and loss of tolerance in primary biliary cholangitis. World 7 Gastroenterol 2016;22:338-48.

27. Danielsson A, Boqvist L, Uddenfeldt P. Epidemiology of primary biliary cirrhosis in a defined rural population in the northern part of Sweden. Hepatology 1990;11:458-64.

28. Tsuji K, Watanabe Y, Van De Water J, et al. Familial primary biliary cirrhosis in Hiroshima. 7 Autoimmun 1999:13:171-8.

29. Bach N, Schaffner F. Familial primary biliary cirrhosis. 7 Hepatol 1994; 20:698-701.

30. Hirschfield GM, Liu X, Xu C, et al. Primary biliary cirrhosis associated with HLA, IL12A, and IL12RB2 variants. N Engl 7 Med 2009;360:2544-55.

31. Mells GF, Floyd JA, Morley KI, et al. Genome-wide association study identifies 12 new susceptibility loci for primary biliary cirrhosis. Nat Genet 2011; 43:329-32.

32. Prince MI, Chetwynd A, Craig WL, et al. Asymptomatic primary biliary cirrhosis: clinical features, prognosis, and symptom progression in a large population based cohort. Gut 2004;53:865-70.

33. Lee J, Belanger A, Doucette JT, et al. Transplantation trends in primary biliary cirrhosis. Clin Gastroenterol Hepatol 2007;5:1313-5

34. Lindor KD, Gershwin ME, Poupon R, et al.; American Association for Study of Liver Diseases. Primary biliary cirrhosis. Hepatology 2009;50:291-308.

35. Sclair SN, Little E, Levy C. Current concepts in primary biliary cirrhosis and primary sclerosing cholangitis. Clin Transl Gastroenterol 2015;6:e109.

36. National Ambulatory Care Reporting System annual report. Ottawa: Canadian Institute for Health Information; 2016.

37. Discharge Abstract Database annual report. Ottawa: Canadian Institute for Health Information; 2016.

38. Canadian Organ Replacement Register report. Ottawa: Canadian Institute for Health Information; 2016.

39. Table: 17-10-0005-01: Population estimates on July 1st, by age and sex. Ottawa: Statistics Canada; updated 2018 Sept. 18.

40. Carey EJ, Ali AH, Lindor KD. Primary biliary cirrhosis. Lancet 2015;386: $1565-75$.

41. Desai S, Peltekian KM. Canadian mortality rates for liver disease: taking a closer look at ICD coding. Can 7 Public Health 2004;95:198-200.

42. Chaurasia RK, Pradhan B, Chaudhary S, et al. Child-Turcotte-Pugh versus model for end stage liver disease score for predicting survival in hospitalized patients with decompensated cirrhosis. 7 Nepal Health Res Counc 2013; 11:9-16.

43. Chawla YK, Kashinath RC, Duseja A, et al. Predicting mortality across a broad spectrum of liver disease - An assessment of model for end-stage liver disease (MELD), Child-Turcotte-Pugh (CTP), and creatinine-modified CTP scores. 7 Clin Exp Hepatol 2011;1:161-8.

44. Table 84-537-X: Life tables, Canada, provinces and territories. Ottawa: Statistics Canada; 2016 (updated 2018 Sept. 18). Available: https://www150.statcan. gc.ca/n1/en/catalogue/84-537-X (accessed 2016 Nov. 1).

45. Delgado J, Sperber AD, Novack V, et al. The epidemiology of primary biliary cirrhosis in southern Israel. Isr Med Assoc 7 2005; 7:717-21.

46. Gross RG, Odin JA. Recent advances in the epidemiology of primary biliary cirrhosis. Clin Liver Dis 2008;12:289-303; viii.

47. Chuang N, Gross RG, Odin JA. Update on the epidemiology of primary biliary cirrhosis. Expert Rev Gastroenterol Hepatol 2011;5:583-90.

48. Borman M, Swain MG. Changing epidemiology and natural history of primary biliary cirrhosis. Clin Liver Dis 2014;3:12-4. doi: 10.1002/cld.305.

49. Canadian Organ Replacement Registry annual report. Ottawa: Canadian Institute for Health Information; 2017. 
50. Kuiper EM, Hansen BE, Metselaar HJ, et al. Trends in liver transplantation for primary biliary cirrhosis in the Netherlands 1988-2008. BMC Gastroenterol 2010;10:144.

51. Myers RP, Shaheen AA, Fong A, et al. Validation of coding algorithms for the identification of patients with primary biliary cirrhosis using administrative data. Can 7 Gastroenterol 2010;24:175-82.

Affiliations: Division of Gastroenterology (Yoshida), University of British Columbia, Vancouver, BC; Division of Gastroenterology (Mason), University of Alberta, Edmonton, Alta.; Division of Digestive Care \& Endoscopy (Peltekian), Dalhousie University and Queen Elizabeth II Health Sciences Centre, Halifax, NS; Toronto Centre for Liver Disease (Shah), University Health Network, Toronto, Ont.; IQVIA (Thiele, Borrelli, Fischer), Mississauga, Ont.

Contributors: Eric Yoshida, Andrew Mason, Kevork Peltekian and Hemant Shah led the writing and review process and were instrumental in providing a clinical perspective in the interpretation of the findings. They provided guidance throughout the conceptualization and development of this work. Aren Fischer, Sherri Thiele and Richard Borrelli proposed the design and analysis of this study, ensured the results were interpreted accurately and within the bounds of the proposed methodology and drafted the article. In addition, they were responsible for liaising with the Canadian Institute for Health Information, from where the study data were captured. All authors revised the article critically for important intellectual content, gave approval of the final version for publication and agreed to be accountable for all aspects of the work.

Funding: This study was supported by funding from Intercept Pharmaceuticals.

Acknowledgements: This study was made possible through the collaborative work of clinical experts in the field of liver and PBC disease. Nicole Capicotto, Ali Tehrani and Dorian Murariu greatly aided in the preparation of this paper.

Supplemental information: For reviewer comments and the original submission of this manuscript, please see www.cmajopen.ca/content/6/4/ E664/suppl/DC1. 